\title{
Research and Practice of Informatization Teaching Reform Based on Ubiquitous Learning Environment and Education Big Data
}

\author{
Zhao Liang, Guili Zhang, Shijiao Qiao \\ Network and Information Center of Southwest Petroleum University, Chengdu, China \\ Email: kathy@swpu.edu.cn
}

How to cite this paper: Liang, Z., Zhang, G. L., \& Qiao, S. J. (2021). Research and Practice of Informatization Teaching Reform Based on Ubiquitous Learning Environment and Education Big Data. Open Journal of Social Sciences, 9, 334-341.

https://doi.org/10.4236/jss.2021.92023

Received: January 19, 2021

Accepted: February 21, 2021

Published: February 24, 2021

Copyright (อ 2021 by author(s) and Scientific Research Publishing Inc. This work is licensed under the Creative Commons Attribution International License (CC BY 4.0).

http://creativecommons.org/licenses/by/4.0/ (c) (i) Open Access

\begin{abstract}
With the continuous accumulation of application data of various business information systems of network and informatization, a campus big data environment with distinctive characteristics of colleges and universities has been formed. Through the in-depth mining and analysis of the existing smart campus data using big data technology, based on the support of intelligent decision-making, personalized adaptive learning analysis and campus security warning of big data, and using the results to feed back the improvement of information literacy of university teachers and students in the era of big data, the construction of ubiquitous learning environment is carried out, which points out the direction for the construction of ubiquitous learning environment to explore the role of big data in improving the quality of education, promoting educational equity and optimizing educational philosophy, so as to improve the ubiquitous education environment.
\end{abstract}

\section{Keywords}

Teaching Big Data, Ubiquitous Learning, Information Teaching Reform

\section{Introduction}

With the rapid development of Internet and information technology, ubiquitous learning has become a basic learning form. Ubiquitous learning breaks the boundaries of time and space of traditional learning, and expands the learning time from traditional classroom to spare time, thus realizing the transition from large-scale to discrete learning behavior. Ubiquitous learning is closely related to 
big data. Big data has achieved great success in the field of business and sociology (Zhou, Kang, \& Gao, 2020). Ubiquitous learning environment provides a good solution for these problems. The emergence of big data technology provides a new solution for the development of ubiquitous learning. Through in-depth analysis of big data demand and operation in ubiquitous learning environment, this paper analyzes education big data, carries out information resource construction, establishes research model, obtains the results and puts them into practice. Finally, it uses the results to feed back the improvement of information literacy of college teachers and students in the era of big data, points out the direction for the construction of ubiquitous learning environment and colleges and universities in the new era to provide advanced experience in talent training.

Through the analysis of the existing smart campus data using big data, using a variety of high-quality information services provided by big data, we can construct the ubiquitous learning environment, improve the ubiquitous education environment, provide data support for the evaluation and improvement of scientific decision-making, students' learning and teachers' teaching, and provide data direction for the reform of classroom teaching ecology (Jin, Zhang, Ba, Song, Yang, \& Song, 2019). Through the exploration of personalized teaching relying on big data technology, colleges and universities will be promoted to a new level in teaching, scientific research and management innovation.

\section{The Impact of Current Higher Education}

The rapid development of Internet and information technology has brought great impact on education. At present, big data is sweeping the field of education, which has brought great changes to human learning, making the learning mode from digital learning to ubiquitous learning. In Colleges and universities, students, teachers and teaching environment are receiving the impact from all directions (Xia \& Cheng, 2018). For example, the change of educational object, the change of teacher's role, the change of teaching environment and so on. The network has brought a diversified teaching environment, and student education is developing rapidly in the direction of informatization and socialization.

\section{The Construction of Ubiquitous Learning Environment}

\subsection{Upgrading of Wireless Network}

The construction of wireless network signal is the basic guarantee of ubiquitous learning. In order to provide convenient communication services for teachers and students to access campus network resources, and provide basic communication guarantee for the development of mobile informatization in Colleges and universities, it is urgent to upgrade the original campus mobile wireless network to campus wireless network, which initially realizes the campus wireless signal access. In order to further improve the quality of wireless signal, the wireless coverage, access speed and total exit bandwidth of wireless network are up- 
graded. Through upgrading and transformation, the wireless signal coverage of the Campus Office, teaching, experiment and student accommodation area is basically realized.

Through the upgrading of wireless network, the quality of wireless network has been greatly improved, and the capacity of wireless network has been basically realized to meet the requirements of high-speed development of university teachers and students. Within the coverage of campus wireless network, faculty can access the campus Internet and campus network resources for free, and students can access campus network resources for free. Users who have opened China mobile wireless account can access mobile Internet and campus network resources in the above areas through campus network account after completing the binding of campus network account and mobile terminal account. Students can visit the campus resource platform and search information on the Internet free of charge at any corner of the campus and at any time through the mobile terminal. The penetration of wireless signals also provides convenience for students' communication, which provides fertile ground for the implementation of ubiquitous learning.

\subsection{Intelligent Authentication}

Intelligent authentication (which is also called imperceptible authentication) is a kind of automatic identification and authentication system by the terminal. Users only need to pass the successful authentication once, and the wireless terminal equipment can automatically record the account information. After that, as long as there is no need of authentication within the coverage of wireless signal, the network can be normally accessed. Imperceptible authentication is an intelligent experience way of wireless network application. Portal protocol authentication is one of the most popular authentication methods, which has some advantages in compatibility. In the process of portal authentication, after the user accesses the network and obtains the address, the gateway will redirect the user who is not authenticated to the authentication portal. The user can directly authenticate through the browser, and then access the network resources after the authentication is successful. It can realize the access and exit of the network. The implementation of intelligent authentication in Colleges and universities avoids the cumbersome repeated login, greatly improves the user experience, and increases the convenience of ubiquitous learning.

\section{Big Data Laboratory Environment Construction}

The construction of big data laboratory environment includes hardware and software. The hardware consists of server, terminal computer and other corresponding supporting equipment. The server is the core hardware platform for the construction of big data laboratory. It not only provides sufficient storage space, memory space, cloud computing resources, mirror scheduling and other resource support for the accumulation of big data laboratory achievements. The 
terminal computer mainly supports teachers, students and researchers to carry out big data experiment courses and scientific research work. The cloud computing cluster access device connects the storage server with the user, and the user calls the image resources in the image warehouse through the container scheduling center. The big data experiment platform adopts B/S structure, and teachers and students use terminal computers to access the resources of big data experiment platform through browser.

The big data laboratory software introduces the big data experiment platform of New Cape, including cloud computing management system, big data course management system, big data online experiment system and big data cloud storage system.

Cloud computing management system is mainly used to monitor the total resource usage of cloud server in real time, as well as the management and operation of mirror warehouse usage.

The big data course management system sets up course contents corresponding to big data, such as Hadoop, R language, python, etc., and can also create new course contents.

The big data online experiment system provides big data experiment cases and supporting experiment manuals. The system is embedded with a variety of big data development environments, including a variety of big data experimental courses.

Big data cloud storage system is mainly for the management of user storage space, which can upload, download and manage various types of files.

\section{Teaching Big Data Collection and Analysis}

Big data provides a forward-looking perspective and direction for the reform of education mode, making it more scientific and innovative. Teaching based on big data is more conducive to personalized development, enrich learning content and improve learning efficiency. The application of big data technology to analyze and measure the learning characteristics of students, through rational data analysis, can have a great impact on the reform and innovation of teaching mode.

Exploration on the application of big data in teaching, finds the relationship between data and draws conclusions. The construction of ubiquitous learning environment provides a strong platform for colleges and universities to carry out network teaching during the epidemic period, innovates the teaching mode and improves the teaching effect.

\subsection{Analysis of Students' Online Behavior}

Analyze the students' online behavior, collects, summarizes and analyzes the students' online time, online times, online course visits, online traffic and social network tracks, so as to provide targeted support and help for students' schoolwork. 


\subsection{Analysis of Teaching Data of Teachers and Students}

Collect and analyze the relevant data in the process of students' curriculum progress. First, the establishment of teaching big data analysis platform, teaching big data will be teachers' information-based teaching into the whole system construction, teachers and students will use information-based means of teaching the whole process of data tracking management, background data analysis, summary of the school curriculum operation, teaching operation data summary and analysis. Second, the establishment of mobile monitoring platform, through the statistical analysis of teaching data through the learning link, to achieve real-time classroom data monitoring, teaching data statistics, network course data, suitable for managers or teaching supervision, teaching monitoring or teaching evaluation. Third, establish a data display platform to realize real-time monitoring of teaching big data, which can display the construction of various resources in Colleges and universities in the form of large screen or splicing screen, digital construction and teaching situation, etc., and display the most core teaching data in Colleges and universities in the most intuitive way.

\subsection{Analysis of Students' Campus Behavior}

Analyze the students' access control system, hot water system, breakfast times, shopping, book borrowing and so on. Using these data, we find the correlation between different data, and explain the relationship between students' campus behavior and students' growth, achievement and employment. In order to predict and intervene the learning situation of students, so that colleges and universities can guide students to better plan their own academic and employment direction.

\subsection{Construction of Adaptive Learning System}

Help colleges and universities to improve students' learning effect with lower teaching cost. It can provide more detailed information for teachers to link students' academic achievements, diagnose learning problems, formulate teaching strategies, and successfully implement personalized education by using student data.

\subsection{Building Teaching Quality Evaluation System}

In the actual teaching of colleges and universities, the analysis of teachers, teaching effect, teaching interaction, learning records, students' evaluation of teaching, course quality and students' performance can be realized. Through the construction of the teaching quality evaluation system, it plays a more detailed role in supporting the data of the whole school. The data used in the assessment of each unit within the school and the declaration of professional titles of each department are all from the big data analysis model using this template. 


\section{Ubiquitous Learning Environment Reconstruction under Big Data}

University data comes from all aspects of digital campus. Through the analysis of education big data, the results can be used for decision-making reference, which has a more specific pertinence for the reconstruction of information resources. The construction of ubiquitous learning environment is a continuous process. Through the introduction of big data technology, we can complete the tracking, analysis and feedback of the learning state of ubiquitous learning participants, establish an optimized ubiquitous learning model, and better provide high-quality and efficient learning resources for college students' autonomous learning.

Under the guidance of big data, we should reconstruct the ubiquitous learning environment, let the data serve the universities, promote the implementation of ubiquitous learning, and then create data value, realize the promotion of personalized learning, realize the transformation of scientific research paradigm, and improve the level of university education management. The results of big data analysis react on the construction of ubiquitous learning environment and promote the further optimization and improvement of ubiquitous learning environment (Xu, Hua, \& Wang, 2018).

\subsection{Data Preparation}

As for the data preparation of big data, according to the development requirements of the "one net" mode in Colleges and universities, teachers can only fill in the business data once, and collect the business data through the "one form" system to realize paperless office.

\subsection{Building Teaching Quality Evaluation System}

Build the teaching quality evaluation system, in the actual teaching of the school to achieve the analysis of teachers, teaching effect analysis, teaching interaction analysis, learning record analysis, students' evaluation of teaching analysis, curriculum quality analysis, student performance analysis, etc. The data used in the assessment of each unit and the declaration of professional title of each department are all from the big data analysis model of this template.

\subsection{Teaching Application of Big Data Laboratory}

The establishment of big data laboratory meets the training needs of students majoring in big data. Through a variety of big data industry project cases and project practice, improve students' hands-on ability, enable students to develop and analyze big data on equipment, and cultivate a variety of practical technical talents of big data. Meet the needs of related professional and teacher training, technical exchange and technical competition. Undertake big data related training tasks, make full use of the laboratory to meet the needs of technical exchange 
and technical competition. Through in-depth analysis of big data industry project cases, theoretical knowledge, practical teaching and big data project practice are integrated to rapidly improve students' big data practice skills. Through the practice of the actual project, students and enterprises can be connected seamlessly.

\section{Practical Application of Research Results}

The various system platforms built in this research, such as MOOC platform to collect teachers' online class information; educational administration system to collect class information, teaching evaluation information; personnel system mobile phone teachers' personnel information; financial system to collect teachers' financial data; scientific research system to collect teachers' scientific research projects, scientific research papers and so on; these business systems provide data channels for teachers' teaching quality, which fundamentally constitute the whole system This paper introduces the integration platform of teaching big data collection and analysis in universities.

The construction of ubiquitous learning environment provides a strong platform support for our school to carry out network teaching during the epidemic period, innovates the teaching mode and improves the teaching effect.

\section{Conclusion}

Big data technology has brought innovation and development to the information construction of colleges and universities (Chen, 2017). Through the exchange, integration and analysis of these data, we can find new knowledge and create new value, thus boosting the all-round reform and innovative development of higher education. The results of big data analysis react on the construction of ubiquitous learning environment, closely integrate the teaching and scientific research innovation, professional personnel training, ubiquitous learning environment construction and big data in colleges and universities, and promote colleges and universities to a new level in big data teaching, scientific research and innovation from a higher starting point.

Using big data technology to promote the development of education is a long process, in which opportunities and challenges coexist. With the continuous development of big data technology, the complexity of big data structure type, data acquisition, data processing and data analysis calculation will gradually increase. Information educators in colleges and universities should firmly grasp the pulse of the times, make comprehensive use of big data, Internet and VR technology to explore new models of future education and serve the construction of lifelong learning system.

\section{Conflicts of Interest}

The authors declare no conflicts of interest regarding the publication of this paper. 


\section{References}

Chen, P. (2017). Big Data Creates a New Paradigm of Teaching and Research. Digital education, 3, 6-9.

Jin, X. C., Zhang, B. L., Ba, Y. F., Song, J. N., Yang, X., \& Song, M. (2019). Research on the Construction of Ubiquitous Learning Environment Mechanism in Colleges and Universities. Journal of Anshun University, 21, 66-74.

Xia, Y. Y., \& Cheng, J. K. (2018). From "Passive Receptive Acquisition" to "Adaptive Learning": The Change of Teaching Paradigm Under the Concept of "Ubiquitous Learning". Higher Science Education, No. 6, 19-24+80.

Xu, Y., Hua, Q. P., \& Wang, X. (2018). Research on the Ubiquitous Learning Mode of Higher Vocational Students with the Concept of Autonomous Learning from the Perspective of Big Data. Fujian Computer, 34, 77-78.

Zhou, Y., Kang, J., \& Gao, Q. Y. (2020). Research on Supervision System of Ubiquitous Environment Integrated Learning Mode Based on Big Data. Journal of Chengde Petroleum College, 22, 38-41. 